\title{
Cross-Ethnic Distribution of Clinically Relevant Cyp2c19 Genotypes and Haplotypes
}

Narazah Mohd Yusoff ${ }^{*}$, Mohamed Saleem ${ }^{1}$, Devaki Nagaya1, Badrul Hisham Yahaya1, Rasmaizatul Akma Rosdi², Nurfadhlina Moosa², Rusli Ismail' ${ }^{2}$ and Tan Soo Choon ${ }^{3}$

${ }^{1}$ Advanced Dental and Medical Institute, University Sains Malaysia, Bertam, 13200 Kepala Batas, Pulau Pinang, Malaysia

${ }^{2}$ Institute for Research in Molecular Medicine (INFORMM), Health Campus, University Sains Malaysia, 16150 Kubang Kerian, Kelantan, Malaysia

${ }^{3}$ Institute for Research in Molecular Medicine, University Sains Malaysia, Minden 11800, Penang, Malaysia

\begin{abstract}
Study background: Knowledge of the drug metabolism phenotype of a patient is critically important to making an informed choice about therapeutic drug prescription. The objective of this study was to determine the prevalence of common clinically relevant variants of the CYP2C19 gene in Malaysian ethnic groups and in other Asian and Middle Eastern populations, and to predict their metabolic phenotypes.
\end{abstract}

Methods: A total of 1103 subjects from six ancestral origins were genotyped for 16 single nucleotide polymorphic (SNP) markers on the CYP2C19 gene to comprehensively understand their allelic distributions. The expectationmaximisation algorithm was used to analyse the genotype data to estimate the maximum likelihood haplotypes in each sample group and to predict the clinical phenogroups.

Results: Of the 16 SNP loci genotyped in the six subpopulations studied, only four SNP markers (rs17885098, rs 4986893, rs4244285 and rs3758581) showed polymorphism (minor allele frequency $>1.0 \%$ ). Nearly half of the Indians (55\%) and Chinese (48.8\%) had at least one copy of the loss-of-function allele. The incidence was relatively lower in Malays (39.3\%), Orang Asli (27.3\%), Javanese (23.8\%) and Saudis (28\%).

Conclusion: These ethnic groups pose a significant risk of drug sensitivity should they are prescribed regular doses of CYP2C 19 substrate.

Keywords: CYP2C19; Polymorphism; Malaysia; Adverse drug reactions; Poor metabolisers

\section{Introduction}

Therapeutic drugs are processed by common biochemical pathways regulated by a class of genes associated with drug absorption, distribution, metabolism, and excretion (ADME). Genetic polymorphisms in these ADME genes alter their pattern of expression and functional heterogeneity and thus are responsible for differences in therapeutic drug response at the inter-individual level and interpopulation levels. Among the core ADME enzymes, most phase I dependent metabolising enzymes are encoded by a repertoire of genes known as cytochrome P450 (CYP) genes, especially by the CYP2C family of genes [1].

CYP family-2 subfamiliy-C peptide-19 (CYP2C19) encodes a monoxygenase that metabolises and bioactivates a wide variety of therapeutic drugs and drug classes, including anticoagulant clopidogrel (Plavix) [2], antimalarial proguanil [3], proton pump inhibitors (e.g., omeprazole and esomeprazole) [4], anticonvulsants (S-mephenytoin and diazepam) [4,5], antidepressants (barbiturates and imipramine) [6,7], HIV-protease inhibitors (e.g., nelfinavir) [8], and $\beta$ =blockers (e.g., propranolol) [9]. The CYP2C19 gene is highly polymorphic. To date, 34 alleles have been catalogued by the Human Cytochrome P450 (CYP) Allele Nomenclature Committee [10]. However, analyses show that only 11 variants, mostly missense point mutations, encode for functionally inactive or unstable enzymes that result in significant differences in pharmacological response. Based on their oxidative and biotransformative metabolic rate of probe xenobiotics, individuals are phenotypically stratified as extensive metabolisers (EMs, representing normal drug metabolism), intermediate metabolisers (IMs), or poor metabolisers (PMs, signifying impaired drug metabolism due to deficiency of functional CYPs). A fourth phenogroup, known as ultra-rapid metabolisers (UM), also has been described. Significant interethnic differences exist in the incidence of PMs among Asians (13-23\%), Africans (6\%), and Caucasians (2-5\%) [11].

Distribution of the CYP2C19 alleles that define these phenogroups is highly variable from one ethnic group to another. Nevertheless, within each ethnic group only a few alleles (commonly ${ }^{\star} 1,{ }^{*} 2,{ }^{*}$, and ${ }^{*} 17$ ) are expected to reach high frequencies. A meaningful clinical classification of a prospective patient into EM, IM, PM, or UM requires genotyping of the common alleles characteristic in the population. CYP2C19* 1 represents the wild type allele that encodes an enzyme with normal (extensive) activity. CYP2C19*2 is defined by a single nucleotide variant on exon 5 (NM_000769.2:c.681G>A rs4244285) that activates a cryptic splice acceptor, and it is the most frequent defective allele in patients with a PM phenotype. CYP2C19*3 has a point mutation on exon 4 (c.636G $>$ A rs4986893) that produces a premature stop codon that results in no in-vitro enzyme activity. Conversely, CYP 2 C $19^{*} 17$ has increased expression and therefore has increased activity, and it confers the UM phenotype. Ethnic Asians have a higher frequency of the ${ }^{\star} 2$ allele (28.9-31.2\%) than African Americans (18.2\%) and

*Corresponding author: Narazah Mohd Yusoff, Advanced Dental and Medical Institute, Universiti Sains Malaysia, Bertam, 13200 Kepala Batas, Pulau Pinang, Malaysia, Tel: +604-5622395; Fax: +604-5622349; E-mail: narazah@amdi.usm.edu.my

Received May 22, 2015; Accepted June 05, 2015; Published June 12, 2015

Citation: Yusoff NM, Saleem M, Nagaya D, Yahaya BH, Rosdi RA, et al. (2015) Cross-Ethnic Distribution of Clinically Relevant Cyp2c19 Genotypes and Haplotypes. J Pharmacogenomics Pharmacoproteomics 6: 147. doi:10.4172/2153-0645.1000147

Copyright: @ 2015 Yusoff NM. This is an open-access article distributed under the terms of the Creative Commons Attribution License, which permits unrestricted use, distribution, and reproduction in any medium, provided the original author and source are credited. 
Caucasians (12.7\%). For individual populations, the highest frequencies of these variants are observed in Japanese (15-22.5\%) [12], Chinese (13-20\%) [13], Indians (12-14\%) [14,15], Koreans (12.6\%) [16], Papua New Guineans (70\%) [17], and individuals from the Vanuatu Islands of Melanesia [18].

Malaysia is a multi-ethnic society with great genetic, linguistic, cultural, and phenotypic diversity. These well-defined social constructs are comprised predominantly of Malays (67.4\%), Chinese $(24.6 \%)$, and Indians (7.3\%) [19], and they remain separated as they seldom intermarry. Other ethnic minorities include an aboriginal group locally known as Orang Asli (OA) [19]; this group, which lives in forest fringe communities isolated from urban areas, forms an inconspicuous scant minority. To date, how the common and rare alleles on the CYP2C19 gene are segregated in these ethnic groups has not been comprehensively studied.

Malaysia's National Pharmaceutical Control Bureau reported 4041 cases of adverse drug reactions (ADRs) during the period from 2004 to 2005 [20]. This rudimentary estimate is anticipated to increase as the population ages and drug-drug interactions increase due to the large number of medications prescribed to older people. Trial and error administration of clinical drugs when a genetic basis has been established on its pharmacokinetic is a dangerous proxy. Thus, knowledge of how clinically significant variants of drug metabolising genes are distributed in groups defined by ethnic characteristics is important for better prescription of therapeutic drugs. In this study we genotyped the 16 alleles on the CYP2C19 gene to determine their frequencies in three major ethnic groups and the indigenous $\mathrm{OA}$ group in Malaysia. The study was extended to include Javanese from Indonesia and Saudis from Saudi Arabia.

\section{Materials and Methods}

\section{Sample}

The 1103 unrelated healthy subjects enrolled in this cross-sectional study consisted of 209 Malays, 201 Chinese, 200 Indians, and 176 OA from Malaysia as well as 185 Javanese from Indonesia and 132 Saudis from Saudi Arabia. Ethnicity and population were defined by all four grandparents belonging to same ethnic group. Blood samples were obtained with informed consent from all participants. This study was approved by the Ethical Committee of Research in Medical Health, Faculty of Medicine, Gadjah Mada University, Indonesia and the Research and Medical Ethics Committee of University Sains Malaysia.

\section{Single nucleotide polymorphism (SNP) genotyping}

Genomic DNA was isolated using the QIAamp DNA Blood Midi Kit (Qiagen Gmbh, Hilden, Germany) according to the manufacturer's instructions. All 1103 samples were genotyped for 16 variants (c.1A>G, rs28399504; c.50T $>$ C, rs55752064; c.55A $>$ C, rs17882687; c.99C $>\mathrm{T}$, rs17885098; c.276G $>$ C, rs17878459; c.395G $>A$, rs72552267; c.431G $>A$, rs17884712; c.449G>A, rs58973490; c.636G >A, rs4986893; c.680C > T, rs6413438; c.681G>A, rs4244285; c.991A >G, rs3758581; c.1228C >T, rs17879685; c.1251A >C, rs17886522; c.1297C >T, rs56337013; c.1473A $>C$, rs55640102) on the CYP2C19 gene using a nested amplification-refractory mutation system (ARMS)-PCR approach.

Briefly, each DNA sample was initially subjected to two multiplex PCR reactions that amplified seven regions of interest on the CYP2C19 gene. The first multiplex reaction $(A)$ was carried out with $0.25 \mu \mathrm{M}$ of each primer (EX1Fw, EX1Rv, EX2Fw, EX2Rv, EX9Fw, and EX9Rv) and $0.6 \mu \mathrm{M}$ of EX8Fw and EX9Rv (Table 1A). The following thermoprofile was used: initial denaturation at $94^{\circ} \mathrm{C}$ for $5 \mathrm{mins}$, followed by 25 cycles of denaturation at $94^{\circ} \mathrm{C}$ for $60 \mathrm{sec}$, annealing at $54^{\circ} \mathrm{C}$ for $45 \mathrm{sec}$, and $72^{\circ} \mathrm{C}$ for $45 \mathrm{sec}$ with a final extension at $72^{\circ} \mathrm{C}$ for $5 \mathrm{~min}$. The second multiplex PCR $(B)$ was performed with $0.6 \mu \mathrm{M}$ of primers EX4Fw and EX4Rv and $0.25 \mu \mathrm{M}$ of primers EX5Fw, EX5Rv,EX7Fw, and EX7Rv using the same cycling conditions, except the annealing temperature was set at $61^{\circ} \mathrm{C}$. These two reactions were carried out with $0.2 \mu \mathrm{g}$ of genomic DNA, 1.0 U Taq DNA polymerase (Biotool ${ }^{\circ}$, B\&M Labs, SA, Madrid, Spain), 1x PCR buffer, $2 \mathrm{mM} \mathrm{MgCl}$, and $0.2 \mathrm{~mm}$ dNTPs (Promega Corporation, Madison, WI, USA). After confirming the presence of the expected bands from the two reactions on 3\% agarose gels, the amplicons from both reactions $A$ and $B$ were mixed and diluted to 1 -in- 25 or 1-in-50 and used as templates in the subsequent ARMS-PCR.

The targeted alleles were ARMS amplified using either of the two allele-specific primers, one complementary to the mutation to be detected and the other complementary to the corresponding normal allele at the same locus. Details about the mutation-specific and wild type sequence-specific primers used are listed in Table 1B. Common characteristics of the thermoprofile used include 15 cycles of denaturation-annealing-extension with diluted PCR amplicons derived from the initial gene amplifications used as the template.

\section{Haplotype phasing and statistical analyses}

Observed and expected genotype frequencies were compared under the Hardy-Weinberg Equilibrium (HWE) theorem using the $\chi^{2}$ goodness-of-fit test. The expectation-maximisation algorithm [21] was used on the genotype data that conformed to HWE to estimate the maximum likelihood haplotypes with frequencies greater than $1 \%$ in each sample group. All statistical analyses were performed using the software Haploview version 4.2 [22].

Inferred haplotypes were annotated using the criteria catalogued by the Human Cytochrome P450 (CYP) Allele Nomenclature Committee [10]. The $C Y P 2 C 19^{\star} 1$ haplotype was assigned by exclusion when derived alleles failed to fit into the defined variant haplotypes.

\section{Results}

All population groups studied were genotyped for 16 biallelic variants on the CYP2C19 gene. Their genotype frequencies are summarised in Table 2. Three markers (rs17882687 $\mathrm{A}>\mathrm{C}$, rs17878459C $>$ T, and $r s 17884712 \mathrm{G}>\mathrm{A}$ ) in the Saudi sample showed statistically significant departure from the HWE $(\mathrm{p}<0.05)$ assumption and were not polymorphic (minor allele frequency $<1 \%$ ). Together with these three loci, seven other SNPs (rs28399504, rs55752064, rs72552267, rs58973490, rs4986893, rs6413438, and rs56337013) across all ethnic groups were homozygous for the wild-type allele and hence were monomorphic.

Haplotypes deduced from expectation-maximisation algorithm with frequencies greater than $1 \%$ in each sub-populations are summarised in Table 3 . Of the wild type ${ }^{*} 1$ allele sub-types, $C Y P 2 C 19^{\star} 1 B$ was invariantly the major sub-haplotype observed in all ethnic groups studied. However, ${ }^{*} 1 B$ sub-haplotype frequency revealed an empirical difference in the OA group relative to the other ethnic groups. This was directly attributed to the 5-6 fold increased prevalence of the $C Y P 2 C 19^{\star} 1 A(31.2 \%)$ sub-haplotype in OA. Apart from this intriguing difference, ${ }^{\star} 1 A$ and ${ }^{\star} 1 C$ sub-types were observed at low frequencies in Malays, Chinese, Javanese and Saudis, whereas both were absent in the Indian sample, making this sub-ethnic group less diverse at the CYP2C19 gene. 
Citation: Yusoff NM, Saleem M, Nagaya D, Yahaya BH, Rosdi RA, et al. (2015) Cross-Ethnic Distribution of Clinically Relevant Cyp2c19 Genotypes and Haplotypes. J Pharmacogenomics Pharmacoproteomics 6: 147. doi:10.4172/2153-0645.1000147

Page 3 of 6

\begin{tabular}{|c|c|c|c|c|c|}
\hline Name & Oligonucleotide sequence & $\begin{array}{l}\text { Annealing } \\
\text { temperature }\end{array}$ & Second primer & $\begin{array}{l}\text { Product size } \\
\quad \text { (bp) }\end{array}$ & Amplification strategy \\
\hline \multicolumn{6}{|c|}{ A. Primers used in the initial multiplex PCR amplifications } \\
\hline Ex1Fw & AGG ACA AAG TCT CCT AAT CTT C & & & \multirow{2}{*}{750} & \\
\hline Ex1Rv & CAA TGA TCT CTT GTA ACA TTG TAC & & & & \\
\hline Ex2Fw & TAA CTG TAT CTC CTT TTC TAG C & & & \multirow{2}{*}{533} & \\
\hline Ex2Rv & AGG TCA GTG ATA GAG AGT ATG & & & & \\
\hline Ex4 Fw & AAG TGT TTT ATA TCT AAT GTT TAC & & & \multirow{2}{*}{304} & \\
\hline Ex4 Rv & CTT CAG GGC TTG GTC AAT ATA G & & & & \\
\hline EX5Fw & CAG AGC TTG GCA TAT TGT ATC & & & \multirow{2}{*}{321} & \\
\hline Ex5 Rv & GTA AAC ACA CAA CTA GTC AAT G & & & & \\
\hline Ex7 Fw & TGT TCC ATT TCT CTC CTT TTC C & & & \multirow[b]{2}{*}{272} & \\
\hline Ex7 Rv & GAA CAT GGA GTT GCA GTG TAG & & & & \\
\hline Ex8 Fw & CAT ATT AAC TTC CCT CAC TTC & & & \multirow[b]{2}{*}{174} & \\
\hline Ex8 Rv & CTT GTA CCC TGA AAC ACA AAG & & & & \\
\hline Ex9 Fw & AGT AAC TTC TCC CTA TGT TTG & & & \multirow{2}{*}{312} & \\
\hline Ex9 Rv & GAT GAC GGG TCA GAA GAA G & & & & \\
\hline \multicolumn{6}{|c|}{ B. Allele specific Primers } \\
\hline rs28399504, c. $1 A>G$ & $\begin{array}{l}\text { ACA AGA GGA GAA GGC TTC AA } \\
\text { ACA AGA GGA GAA GGC TTC AG }\end{array}$ & \multirow{2}{*}{61} & Ex 1Rv & 288 & \multirow{2}{*}{ Duplexed with $\S$} \\
\hline c. $395 \mathrm{G}>\mathrm{A}, \mathrm{rs} 72552267$ & $\begin{array}{l}\text { CTC CCT CAT GAC GCT GCG } \\
\text { CTC CCT CAT GAC GCT GCA }\end{array}$ & & Ex $2 R v$ & 134 & \\
\hline c.50T>C, rs55752064 & $\begin{array}{l}\text { CTC TCA TGT TTG CTT CTC CC } \\
\text { CTC TCA TGT TTG CTT CTC CT }\end{array}$ & \multirow{2}{*}{61} & Ex 1Rv & 239 & \multirow{2}{*}{ Duplexed with $\S$} \\
\hline c. $1297 \mathrm{C}>\mathrm{T}, \mathrm{rs} 56337013$ & $\begin{array}{l}\text { ATG TTT GTT ATT TTC AGG AAA AC } \\
\text { ATG TTT GTT ATT TTC AGG AAA AT }\end{array}$ & & Ex9 Rv & 298 & \\
\hline c. $55 \mathrm{~A}>\mathrm{C}, \mathrm{rs} 17882687$ & $\begin{array}{l}\text { CAG AGC TCT GTC TCC AGA T } \\
\text { CAG AGC TCT GTC TCC AGA G }\end{array}$ & \multirow{2}{*}{61} & Ex1Fw & 554 & \multirow{2}{*}{ Duplexed with $\S$} \\
\hline c. $1228 \mathrm{C}>\mathrm{T}$, rs 17879685 & $\begin{array}{l}\text { CCA GAG ATG TTT GAC CCT T } \\
\text { CCA GAG ATG TTT GAC CCT C }\end{array}$ & & Ex8Rv & 122 & \\
\hline c. $99 \mathrm{C}>\mathrm{T}, \mathrm{rs} 17885098$ & $\begin{array}{l}\text { AAT CAC TGG GAG AGG AGT G } \\
\text { AAT CAC TGG GAG AGG AGT A }\end{array}$ & \multirow{2}{*}{61} & Ex1Fw & 598 & \multirow{2}{*}{ Duplexed with $\S$} \\
\hline c. $636 \mathrm{G}>\mathrm{A}, \mathrm{rs} 4986893$ & $\begin{array}{l}\text { GTA AGC ACC CCC TGG } \\
\text { GTA AGC ACC CCC TGA }\end{array}$ & & Ex4Rv & 109 & \\
\hline c. $276 \mathrm{G}>\mathrm{C}, \mathrm{rs} 17878459$ & $\begin{array}{l}\text { GCC TCT TCC AGA AAA CTC G } \\
\text { GCC TCT TCC AGA AAA CTC C }\end{array}$ & \multirow{2}{*}{63} & \multirow{2}{*}{ Ex2Fw } & \multirow{2}{*}{$\begin{array}{l}147 \\
488\end{array}$} & \multirow{2}{*}{ Duplexed with $\ddagger$} \\
\hline c. $449 \mathrm{G}>\mathrm{A}, \mathrm{rs} 58973490$ & $\begin{array}{l}\text { ACT CCT CCA CAA GGC AGC } \\
\text { ACT CCT CCA CAA GGC AGT }\end{array}$ & & & & \\
\hline c. $431 \mathrm{G}>\mathrm{A}, \mathrm{rs} 17884712$ & $\begin{array}{l}\text { GAG GAG CAT TGA GGA CCG } \\
\text { GAG GAG CAT TGA GGA CCA }\end{array}$ & 61 & Ex2Rv & 98 & $\begin{array}{l}\text { With amplicons from PCR } \\
\qquad A+B^{\ddagger}\end{array}$ \\
\hline c. $681 G>A, r s 4244285$ & $\begin{array}{l}\text { CTA TCA TTG ATT ATT TCC CA } \\
\text { CTA TCA TTG ATT ATT TCC CG }\end{array}$ & 57 & Ex5Rv & 231 & $\begin{array}{l}\text { With amplicons from PCR } \\
\qquad A+B^{\S}\end{array}$ \\
\hline c. $680 \mathrm{C}>\mathrm{T}, \mathrm{rs} 6413438$ & $\begin{array}{l}\text { CCA CTA TCA TTG ATT ATT TCC C } \\
\text { CCA CTA TCA TTG ATT ATT TCC T }\end{array}$ & \multirow{2}{*}{61} & Ex5Rv & 234 & \multirow{2}{*}{ Duplexed with $\S$} \\
\hline c. $991 \mathrm{~A}>\mathrm{G}, \mathrm{rs} 3758581$ & $\begin{array}{l}\text { GCT CCG GTT TCT GCC AAT } \\
\text { GCT CCG GTT TCT GCC AAC }\end{array}$ & & Ex7Fw & 95 & \\
\hline c. $1251 \mathrm{~A}>\mathrm{C}, \mathrm{rs} 17886522$ & $\begin{array}{l}\text { ACT TTC TGG ATG AAG GTG GC } \\
\text { ACT TTC TGG ATG AAG GTG GA }\end{array}$ & \multirow{2}{*}{61} & Ex8Rv & 100 & \multirow{2}{*}{ Duplexed with $\ddagger$} \\
\hline c. $1473 \mathrm{~A}>\mathrm{C}$, rs 55640102 & $\begin{array}{l}\text { CAG ACC ATC TGT GCT TCT T } \\
\text { CAG ACC ATC TGT GCT TCT G }\end{array}$ & & Ex9Fw & 231 & \\
\hline$\S$ Amplico & $A+B$ mixed and diluted to $1: 25$ with $P C R$ & ; ‡ Amplicons & A+B mixed and & do to $1: 50 \mathrm{wi}$ & R buffer \\
\hline
\end{tabular}

Table 1: Primers used in the initial multiplex PCR amplifications and allele specific PCR reactions with their cycling conditions. 
The commonest loss-of-function allele observed was the CYP2C19*2A sub-haplotype; it was found in all ethnic groups studied at varying frequencies ranging from $9.3 \%$ in Saudis to $28.5 \%$ in Indians. The ${ }^{*} 3$ allele was present at appreciable frequencies only in the three major ethnic groups from Malaysia, with the highest prevalence in Chinese (3.5\%). Less frequent haplotypes ${ }^{*} 12(\mathrm{c} .1473 \mathrm{~A}>\mathrm{C}$, rs55640102) and ${ }^{\star} 13$ (c.1228C $>\mathrm{T}$, rs 17879685 ) were private and found only in the Saudi population at frequencies of $1.8 \%$ and $1 \%$, respectively. None of the populations studied had ${ }^{*} 4(\mathrm{c} .1 \mathrm{~A}>\mathrm{G}, \mathrm{rs} 28399504),{ }^{\star} 5(\mathrm{c} .1297 \mathrm{C}>\mathrm{T}$, rs56337013), ${ }^{\star} 6(\mathrm{c} .395 \mathrm{G}>\mathrm{A}, \mathrm{rs} 72552267),{ }^{\star} 10$ (c.680C $\left.>\mathrm{T}, \mathrm{rs} 6413438\right)$, ${ }^{\star} 11,{ }^{*} 14(\mathrm{c} .1473 \mathrm{~A}>\mathrm{C}, \mathrm{rs} 55640102)$, and ${ }^{\star} 15$.

Based on the functional genotypes (Table 3) as the determinants of metabolic phenotypes, $33.5 \%$ of Malays , $32.3 \%$ of Chinese, $44.5 \%$ of Indians, $22.7 \%$ of OA, $21.6 \%$ of Javanese, and $22 \%$ of Saudis were predicted to be IMs, whereas $5.7 \%$ of Malays, $16.4 \%$ of Chinese, $10.5 \%$ of Indians, $4.5 \%$ of OA, $2.2 \%$ of Javanese, and $1.5 \%$ of Saudis were PMs. The Saudi cohort also contained unknown phenotypes consisting of individuals heterozygous for ${ }^{\star} 1 /{ }^{\star} 12$ and ${ }^{*} 1 /{ }^{*} 13$.

\section{Discussion}

The CYP2C19 gene contains many variants with likely functional consequences. Acute deficiency of frequency data beyond the CYP2C19*2 (c.681G >A, rs4244285) and *3 (c.636G $>$ A, rs4986893) variants that are commonly assessed impelled us to further genotype 16 variants within the six Asian ethnic groups from a variety of ancestral origins to comprehensively understand their allelic distributions and predict the clinical phenogroups. As shown in Table 4, the studied loci are the defining mutations that readily characterise at least 13 alleles: ${ }^{\star} 2-{ }^{*} 6$ and ${ }^{*} 9-{ }^{*} 15$, and ${ }^{*} 1$ by exclusion. Most allelic determinations are apparently straightforward and can be identified by genotyping the defined loci (e.g., c. $681 \mathrm{G}>\mathrm{A}$ designated for ${ }^{\star} 2$, c. $636 \mathrm{G}>\mathrm{A}$ for ${ }^{\star}$, and c. $1 \mathrm{~A}>\mathrm{G}$ for $\left.{ }^{\star} 4\right)$.

Our data show that the Malaysian ethnic groups contain a wide range of PMs that involve ${ }^{\star} 2$ and ${ }^{*} 3$ in various genotypic combinations. In particular, greater than $10 \%$ of the Chinese and Indians subpopulations were PMs. Therefore, in our exposition, genotyping the CYP2C19 gene, at least for the c.681G $>$ A, rs4244285 $\left({ }^{*} 2\right)$ and c.636G $>$ A, rs4986893 $\left({ }^{*} 3\right)$ alleles, may be crucial for reducing the incidence of ADR and for gauging the individual's response to CYP2C19 substrate drugs. For example, the inactive prodrug clopidogrel is an important CYP2C19 substrate medication used to reduce cardiovascular events; pre-treatment genetic testing to determine the metabolic status of the patient may be helpful to determine the clinical outcome of treatment with this drug. This is particularly important in a community such as Malaysian, in which the incidence of acute coronary syndrome (ACS) is high (currently 141 per 100,000 population per year, with an impatient mortality rate of 7\%) [23]. Although there is no general consensus about genetic testing of patients, information about clopidogrel sensitivity clearly would be useful for determining optimised dosage if the patient needs it for management of ACS.

The results of this study clearly show ethnic heterogeneity with regard to loss of function alleles associated with the CYP2C19 gene. Nearly half of the Indians (55\%) and Chinese (48.8\%) have at least one copy of the loss of function allele (Table 3 ). Although the incidence was relatively lower in Malays (39.3\%), OA (27.3\%), Javanese (23.8\%), and Saudis $(28 \%)$, these cohorts pose a significant risk for drug sensitivity should they are prescribed the regular doses of CYP2C19 substrate drugs. Similar frequencies have been reported from different ethnic groups: $50 \%$ of Asians, $34 \%$ Africans, and at least $25 \%$ of Caucasians reportedly carry at least a single copy of a loss of function allele. In our samples, these differences were in principle attributed to four polymorphic SNPs loci (rs17885098, rs4986893, rs4244285, and rs3758581) used to infer the haplotypes.

The CYP2C19*1A sub-haplotype, which is denoted by the absence of derived alleles, was not common in any group tested except OA. The distinctly high presence of ${ }^{*} 1 A$ in OA made it the second most common functionally normal sub-haplotype after ${ }^{*} 1 B$. This result supports the evolutionary premise that ancestral alleles are more common in aboriginal populations such as OA, which form small pockets of endogamous communities in Malaysia that live in isolation disconnected from urban sub-populations. Invariably, ${ }^{*} 1 B$ was the major sub-haplotype in all the six ethnic groups. This is the result of the widespread variant alleles $\mathrm{T}$ and $\mathrm{G}$ at the c.99C $>\mathrm{T}$ ( $\mathrm{rs} 17885098$ ) and c.991A $>\mathrm{G}$ (rs3758581) loci, which apparently reached fixation in all ethnic groups except the aboriginal OA group. Near fixation of these variant alleles has been observed globally in Europeans, Asians, and Sub-Saharan Africans [24,25]. Increased heterozygosity at these two loci within the ancestral OA cohort probably reflects a benign stochastic process or that it confers resistance to an unknown aetiology. Despite the missense mutation c. $991 \mathrm{~A}>\mathrm{G}, \mathrm{rs} 3758581$ present in ${ }^{*} 1 B$ and ${ }^{*} 1 C$, it remains functionally unimpaired and no different from the ${ }^{\star} 1 A$. $C Y P 2 C 19^{*} 1 B(v)$ observed in OA and Saudis is presumed to be a variant of ${ }^{*} 1 B$, which differed by a single nucleotide at 991A $>\mathrm{G}(\mathrm{rs3758581})$. Similarly, another variant $C Y P 2 C 19^{*} 1 C(v)$ which was only observed in the Javanese cohort, has a single nucleotide difference from the less frequent ${ }^{\star} 1 C$.

CYP2C19* 1 allele determination by exclusion may overestimate the EM phenotype. A recent study on a Saudi sample revealed that nearly $46 \%$ of its sample contained the ${ }^{\star} 17$ allele, with a gene frequency of $26.9 \%$ [26]. However, the genotyping panel used in the present study did not include the ${ }^{\star} 17$ determinant (c.-806C $>\mathrm{T}$, rs12248560), and hence the ${ }^{\star} 1$ allele determined by exclusion in our Saudi cohort likely was overestimated, resulting in overestimation of the presence of the $\mathrm{EM}$ phenotype. The substitution at c. $-806 \mathrm{C}>\mathrm{T}$ at the promoter region $\left({ }^{*} 17\right)$ increases the transcription activity and thus is associated with the UM phenotype.

Our understanding of the consequences of CYP2C19 variants is far from perfect. Some variants are apparently straightforward and their phenotype is predictable, such as ${ }^{*} 2$ and ${ }^{*} 3$. However, the contributions of ${ }^{*} 12$ and ${ }^{*} 13$ to genotypes such as ${ }^{*} 1 /{ }^{*} 12$ and ${ }^{*} 1 /{ }^{*} 13$ observed in the Saudi cohort remains unclear.

The goals of this study were to identify polymorphisms of alleles on the CYP2C19 gene and to determine the distribution of phenotypes within six different populations. $C Y P 2 C 19^{*} 2$ was found at various frequencies across all sub-populations studied, thus it constituted the predominant dysfunctional allele. The data also revealed the presence of ${ }^{*} 3$ in Malays, Chinese, and Indians at low frequencies but it was not present in the Javanese, OA, and Saudis. Taken together, the inferred phenotypes were due to nucleotide substitutions at four loci (rs17885098, rs4986893, rs4244285, and rs3758581). Nucleotide diversity was intuitively high in Saudis, and this population also had additional SNPs (rs17879685 (c.1228C >T) and rs55640102 (c.1473A>C), characteristic of ${ }^{*} 12$ and ${ }^{*} 13$, respectively). It is unclear at present whether genotyping of CYP2C19 will materially change the overall rate of ADRs in these sub-populations, but these results suggest that this approach would be successful. 
Citation: Yusoff NM, Saleem M, Nagaya D, Yahaya BH, Rosdi RA, et al. (2015) Cross-Ethnic Distribution of Clinically Relevant Cyp2c19 Genotypes and Haplotypes. J Pharmacogenomics Pharmacoproteomics 6: 147. doi:10.4172/2153-0645.1000147

Page 5 of 6

\begin{tabular}{|c|c|c|c|c|c|c|c|}
\hline \multirow{2}{*}{$\begin{array}{l}\text { Nucleotide change in } \\
\text { cDNA, NCBI SNP ID }\end{array}$} & \multirow{2}{*}{ Genotype } & \multicolumn{6}{|c|}{ Genotype Frequencies, N (\%) } \\
\hline & & Malays $(n=209)$ & Chinese $(n=201)$ & Indians $(n=200)$ & Orang Asli $(n=176)$ & Javanese $(n=185)$ & Saudis $(n=132)$ \\
\hline c. $1 A>G, r s 28399504$ & $\begin{array}{l}\text { AA } \\
\text { AG } \\
\text { GG }\end{array}$ & $209(100 \%)$ & $201(100 \%)$ & $200(100 \%)$ & $176(100 \%)$ & $185(100 \%)$ & $132(100 \%)$ \\
\hline c. $50 \mathrm{~T}>\mathrm{C}, \mathrm{rs} 55752064$ & $\begin{array}{l}\text { TT } \\
\text { CT } \\
\text { CC }\end{array}$ & $209(100 \%)$ & $201(100 \%)$ & $200(100 \%)$ & $176(100 \%)$ & $185(100 \%)$ & $132(100 \%)$ \\
\hline c. $55 \mathrm{~A}>\mathrm{C}, \mathrm{rs} 17882687$ & $\begin{array}{l}\text { AA } \\
\text { AC } \\
\text { CC }\end{array}$ & $209(100 \%)$ & $201(100 \%)$ & $200(100 \%)$ & $176(100 \%)$ & $185(100 \%)$ & $\begin{array}{c}130(98.5 \%)^{*} \\
2(1.5 \%)^{*} \\
0\end{array}$ \\
\hline c. $99 \mathrm{C}>\mathrm{T}, \mathrm{rs} 17885098$ & $\begin{array}{l}\text { CC } \\
\text { CT } \\
\text { TT }\end{array}$ & $\begin{array}{c}4(1.9 \%) \\
27(12.9 \%) \\
178(85.2 \%)\end{array}$ & $\begin{array}{c}3(1.5 \%) \\
30(14.9 \%) \\
168(83.6 \%)\end{array}$ & $\begin{array}{c}0 \\
10(5 \%) \\
190(95 \%)\end{array}$ & $\begin{array}{c}16(9.1 \%) \\
82(46.9 \%) \\
77(44 \%)\end{array}$ & $\begin{array}{c}1(0.5 \%) \\
25(13.5 \%) \\
159(85.9 \%)\end{array}$ & $\begin{array}{c}- \\
24(18.2 \%) \\
108(81.8 \%)\end{array}$ \\
\hline c. $276 \mathrm{G}>\mathrm{C}, \mathrm{rs} 17878459$ & $\begin{array}{l}\text { GG } \\
\text { CG } \\
\text { CC }\end{array}$ & $209(100 \%)$ & $201(100 \%)$ & $200(100 \%)$ & $176(100 \%)$ & $185(100 \%)$ & $\begin{array}{c}131(97.7 \%)^{*} \\
1(1.5 \%)^{*}\end{array}$ \\
\hline c.395G>A, rs72552267 & $\begin{array}{l}\text { GG } \\
\text { AG } \\
\text { AA }\end{array}$ & $209(100 \%)$ & $201(100 \%)$ & $200(100 \%)$ & $176(100 \%)$ & $185(100 \%)$ & $132(100 \%)$ \\
\hline c. $431 \mathrm{G}>\mathrm{A}, \mathrm{rs} 17884712$ & $\begin{array}{l}\text { GG } \\
A G \\
A A\end{array}$ & $209(100 \%)$ & $201(100 \%)$ & $200(100 \%)$ & $176(100 \%)$ & $185(100 \%)$ & $\begin{array}{c}130(98.5 \%)^{*} \\
2(1.5 \%)^{*}\end{array}$ \\
\hline c. $449 \mathrm{G}>\mathrm{C}, \mathrm{rs} 58973490$ & $\begin{array}{l}\text { GG } \\
\text { CG } \\
\text { CC }\end{array}$ & $209(100 \%)$ & $201(100 \%)$ & $200(100 \%)$ & $176(100 \%)$ & $185(100 \%)$ & $132(100 \%)$ \\
\hline c. $636 \mathrm{G}>\mathrm{A}, \mathrm{rs} 4986893$ & $\begin{array}{l}\text { GG } \\
\text { AG } \\
\text { AA }\end{array}$ & $\begin{array}{c}199(95.2 \%) \\
10(4.8 \%)\end{array}$ & $\begin{array}{c}186(92.5 \%) \\
14(7.0 \%) \\
1(0.5 \%)\end{array}$ & $\begin{array}{c}193(96.5 \%) \\
7(3.5 \%) \\
0\end{array}$ & $176(100 \%)$ & $185(100 \%)$ & $132(100 \%)$ \\
\hline c. $680 \mathrm{C}>\mathrm{T}, \mathrm{rs} 6413438$ & $\begin{array}{l}\text { CC } \\
\text { CT } \\
\text { TT }\end{array}$ & $209(100 \%)$ & $201(100 \%)$ & $200(100 \%)$ & $176(100 \%)$ & $185(100 \%)$ & $132(100 \%)$ \\
\hline c. $681 G>A, r s 4244285$ & $\begin{array}{l}\text { GG } \\
\text { AG } \\
\text { AA }\end{array}$ & $\begin{array}{c}137(65.6 \%) \\
60(28.7 \%) \\
12(5.7 \%)\end{array}$ & $\begin{array}{c}117(58.2 \%)^{\star} \\
65(32.3 \%)^{*} \\
19(9.5 \%)^{*}\end{array}$ & $\begin{array}{l}96(48 \%) \\
84(42 \%) \\
20(10 \%)\end{array}$ & $\begin{array}{c}128(72.7 \%) \\
41(23.3 \%) \\
7(4.0 \%)\end{array}$ & $\begin{array}{c}141(76.2 \%) \\
40(21.6 \%) \\
4(2.2 \%)\end{array}$ & $\begin{array}{c}102(77.3 \%) \\
28(21.2 \%) \\
2(1.5 \%)\end{array}$ \\
\hline c. $991 \mathrm{~A}>\mathrm{G}, \mathrm{rs} 3758581$ & $\begin{array}{l}\text { AA } \\
\text { AG } \\
\text { GG }\end{array}$ & $\begin{array}{c}- \\
8(3.8 \%) \\
201(96.2 \%)\end{array}$ & $\begin{array}{c}- \\
20(10 \%) \\
181(90 \%)\end{array}$ & $\begin{array}{c}- \\
4(2 \%) \\
196(98 \%)\end{array}$ & $\begin{array}{c}17(9.6 \%) \\
83(47.2 \%) \\
76(43.2 \%)\end{array}$ & $\begin{array}{c}- \\
12(6.5 \%) \\
173(93.5 \%)\end{array}$ & $\begin{array}{c}- \\
38(28.8 \%) \\
94(71.2 \%)\end{array}$ \\
\hline c. $1228 \mathrm{C}>\mathrm{T}, \mathrm{rs} 17879685$ & $\begin{array}{l}\text { CC } \\
\text { CT } \\
\text { TT }\end{array}$ & $209(100 \%)$ & $201(100 \%)$ & $200(100 \%)$ & $176(100 \%)$ & $185(100 \%)$ & $\begin{array}{c}126(95.5 \%) \\
6(4.5 \%)\end{array}$ \\
\hline c. $1251 \mathrm{~A}>\mathrm{C}, \mathrm{rs} 17886522$ & $\begin{array}{l}\text { AA } \\
\text { AC } \\
\text { CC }\end{array}$ & $209(100 \%)$ & $201(100 \%)$ & $200(100 \%)$ & $\begin{array}{c}170(96.6 \%) \\
6(3.4 \%)\end{array}$ & $\begin{array}{c}174(94.1 \%) \\
11(5.9 \%) \\
0\end{array}$ & $132(100 \%)$ \\
\hline c. $1297 \mathrm{C}>\mathrm{T}, \mathrm{rs} 56337013$ & $\begin{array}{l}\text { CC } \\
\text { CT } \\
\text { TT }\end{array}$ & $209(100 \%)$ & $201(100 \%)$ & $200(100 \%)$ & $176(100 \%)$ & $185(100 \%)$ & $132(100 \%)$ \\
\hline c. $1473 \mathrm{~A}>\mathrm{C}, \mathrm{rs} 55640102$ & $\begin{array}{l}\mathrm{AA} \\
\mathrm{AC} \\
\mathrm{CC}\end{array}$ & $209(100 \%)$ & $201(100 \%)$ & $200(100 \%)$ & $176(100 \%)$ & $185(100 \%)$ & $\begin{array}{c}126(95.5 \%) \\
6(4.5 \%)\end{array}$ \\
\hline
\end{tabular}

Table 2: Genotype frequencies of CYP2C19 alleles in Malays, Chinese, Indians, Orang Asli, Javanese and Saudis.

\begin{tabular}{|c|c|c|c|c|c|c|c|c|c|}
\hline \multirow{3}{*}{$\begin{array}{c}\text { Subpopulations } \\
\text { Genotypes }\end{array}$} & \multicolumn{9}{|c|}{ Phenotypes } \\
\hline & \multirow{2}{*}{$\begin{array}{c}\text { Extensive } \\
{ }^{*} 1 /{ }^{*} 1\end{array}$} & \multicolumn{3}{|c|}{ Intermediate } & \multicolumn{3}{|c|}{ Poor } & \multicolumn{2}{|c|}{ Unknown } \\
\hline & & $* 1 /{ }^{*} 2$ & $* 1 / * 3$ & *2/*12 & ${ }^{*} 2 /{ }^{*} 2$ & ${ }^{*} 2 /{ }^{*} 3$ & $* 3 /{ }^{*} 3$ & $* 1 / * 12$ & $* 1 / * 13$ \\
\hline Malay, N (\%) & $127(60.7 \%)$ & $60(28.7 \%)$ & $10(4.8 \%)$ & - & $12(5.7 \%)$ & - & - & & \\
\hline Chinese, N (\%) & $103(51.2 \%)$ & $61(30.3 \%)$ & $4(2 \%)$ & - & $23(11.4 \%)$ & $9(4.5 \%)$ & $1(0.5 \%)$ & - & - \\
\hline Indian, N (\%) & $90(45.0 \%)$ & $83(41.5 \%)$ & $6(3.0 \%)$ & - & $20(10.0 \%)$ & $1(0.5 \%)$ & - & & \\
\hline OA, N (\%) & $128(72.7 \%)$ & $40(22.7 \%)$ & - & - & $8(4.5 \%)$ & - & - & - & - \\
\hline Javanese, N (\%) & $141(76.2)$ & $40(21.6)$ & - & - & $4(2.2)$ & - & - & & \\
\hline Saudis, N (\%) & $95(72.0 \%)$ & $28(21.2 \%)$ & - & $1(0.75 \%)$ & $2(1.5 \%)$ & & - & $4(3.0 \%)$ & $2(1.5 \%)$ \\
\hline
\end{tabular}

Table 3: Comparison of CYP2C19 allele frequencies within various ethnic groups. 
Citation: Yusoff NM, Saleem M, Nagaya D, Yahaya BH, Rosdi RA, et al. (2015) Cross-Ethnic Distribution of Clinically Relevant Cyp2c19 Genotypes and Haplotypes. J Pharmacogenomics Pharmacoproteomics 6: 147. doi:10.4172/2153-0645.1000147

Page 6 of 6

\begin{tabular}{|c|c|c|c|c|c|c|c|c|c|c|c|c|c|c|c|c|c|c|c|c|c|c|}
\hline \multirow{2}{*}{ Haplotype } & \multirow{2}{*}{ 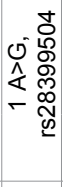 } & \multirow{2}{*}{ 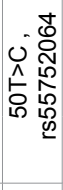 } & \multirow{2}{*}{ 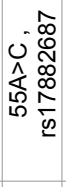 } & \multirow{2}{*}{ 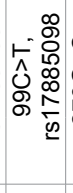 } & \multirow{2}{*}{ 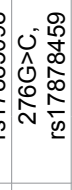 } & \multirow{2}{*}{\multicolumn{2}{|c|}{ 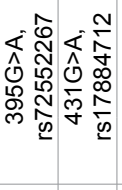 }} & \multirow{2}{*}{ 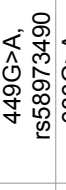 } & \multirow{2}{*}{ 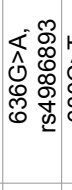 } & \multirow{2}{*}{ 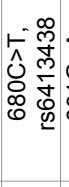 } & \multirow{2}{*}{ 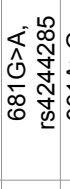 } & \multirow{2}{*}{\multicolumn{2}{|c|}{ 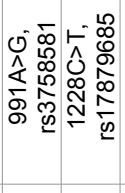 }} & \multirow{2}{*}{ 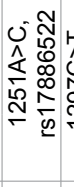 } & \multirow{2}{*}{ 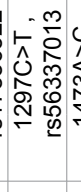 } & \multirow{2}{*}{ 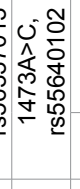 } & \multicolumn{6}{|c|}{ Ethnic groups Haplotype frequencies } \\
\hline & & & & & & & & & & & & & & & & & Malays & Chinese & Indians & $\begin{array}{c}\text { Orang } \\
\text { Asli }\end{array}$ & Javanese & Saudis \\
\hline CYP2C19*1B & A & $\mathrm{T}$ & A & $\mathrm{T}$ & G & G & G & G & G & C & G & G & C & A & C & A & $72.1 \%$ & $63.4 \%$ & $67.2 \%$ & $51.3 \%$ & $79.8 \%$ & $73.7 \%$ \\
\hline CYP2C19*2A & A & $\mathrm{T}$ & A & $\mathrm{T}$ & G & G & G & G & G & C & A & G & C & A & C & A & $17.4 \%$ & $24.1 \%$ & $28.5 \%$ & $14.9 \%$ & $12.9 \%$ & $9.3 \%$ \\
\hline CYP2C19*1A & A & $\mathrm{T}$ & A & C & G & G & G & G & G & C & G & A & C & A & C & A & $1.7 \%$ & $5.0 \%$ & - & $31.2 \%$ & $3.2 \%$ & $6.6 \%$ \\
\hline CYP2C19*1C & A & T & A & C & G & G & G & G & G & C & G & G & C & A & C & A & $3.9 \%$ & $2.5 \%$ & - & $<1.0$ & $1.0 \%$ & $1.4 \%$ \\
\hline $\begin{array}{l}\text { CYP2C19*1 } \\
\text { (variant of *1B) }\end{array}$ & A & $\mathrm{T}$ & A & $\mathrm{T}$ & G & G & G & G & G & C & G & A & C & A & C & A & - & - & - & $1.5 \%$ & - & $3.9 \%$ \\
\hline $\begin{array}{c}\text { CYP2C19*1 } \\
\text { (variant of *1C) }\end{array}$ & A & $\mathrm{T}$ & A & C & G & G & G & G & G & C & G & G & C & C & C & A & - & - & - & - & $3.0 \%$ & - \\
\hline CYP2C19*2 & A & $\mathrm{T}$ & A & C & G & G & G & G & G & C & A & G & C & A & C & A & $2.5 \%$ & 1.1 & $1.5 \%$ & & & \\
\hline CYP2C19*3A & A & $\mathrm{T}$ & A & $\mathrm{T}$ & G & G & G & G & A & C & G & G & C & A & C & A & $2.4 \%$ & $3.5 \%$ & $1.7 \%$ & & & \\
\hline CYP2C19*12 & A & $\mathrm{T}$ & A & $\mathrm{T}$ & G & G & G & G & G & C & G & A & C & A & C & C & - & - & & - & - & $1.8 \%$ \\
\hline CYP2C $19 * 13$ & A & $\mathrm{T}$ & A & $\mathrm{T}$ & G & G & G & G & G & C & G & G & $\mathrm{T}$ & A & C & A & - & - & & - & - & $1.0 \%$ \\
\hline
\end{tabular}

Table 4: Haplotypes observed for study populations. Haplotypes observed in singletons are not presented here.

\section{Acknowledgement}

This study was supported by RUC grant 1001/PSK/8620013, University Sains Malaysia

\section{References}

1. Daly AK (2004) Pharmacogenetics of the cytochromes P450. Curr Top Med Chem 4: 1733-1744.

2. Nasyuhana Sani Y, Sheau Chin L, Luen Hui L, Mohd Redhuan Shah Edwin NE, Teck Hwa G, et al. (2013) The CYP2C19\&\#x2a;1/\&\#x2a;2 Genotype Does Not Adequately Predict Clopidogrel Response in Healthy Malaysian Volunteers. Cardiol Res Pract 2013: 128795.

3. Wright JD, Helsby NA, Ward SA (1995) The role of S-mephenytoin hydroxylase (CYP2C19) in the metabolism of the antimalarial biguanides. $\mathrm{Br} \mathrm{J}$ Clin Pharmacol 39: 441- 444

4. Andersson T, Regårdh CG, Lou YC, Zhang Y, Dahl ML, et al. (1992) Polymorphic hydroxylation of S-mephenytoin and omeprazole metabolism in Caucasian and Chinese subjects. Pharmacogenetics 2: 25-31.

5. Ono S, Hatanaka T, Miyazawa S, Tsutsui M, Aoyama T, et al. (1996) Human liver microsomal diazepam metabolism using cDNA-expressed cytochrome P450s: role of CYP2B6, 2C19 and the 3A subfamily. Xenobiotica 26: 11551166.

6. Küpfer A, Branch RA (1985) Stereoselective mephobarbital hydroxylation cosegregates with mephenytoin hydroxylation. Clin Pharmacol Ther 38: 414418.

7. Baumann $\mathrm{P}$, Jonzier-Perey $\mathrm{M}$, Koeb $\mathrm{L}$, Küpfer $\mathrm{A}$, Tinguely $\mathrm{D}$, et al (1986) Amitriptyline pharmacokinetics and clinical response: II. Metabolic polymorphism assessed by hydroxylation of debrisoquine and mephenytoin Int Clin Psychopharmacol 1: 102-112.

8. Hirani VN, Raucy JL, Lasker JM (2004) Conversion of the HIV protease inhibitor nelfinavir to a bioactive metabolite by human liver CYP2C19. Drug Metab Dispos 32: 1462-1467.

9. Ward SA, Walle T, Walle UK, Wilkinson GR, Branch RA (1989) Propranolol's metabolism is determined by both mephenytoin and debrisoquin hydroxylase activities. Clin Pharmacol Ther 45: 72-79.

10. Sim SC, Ingelman-Sundberg M (2010) The Human Cytochrome P450 (CYP) Allele Nomenclature website: a peer-reviewed database of CYP variants and their associated effects. Hum Genomics 4: 278-281.

11. Goldstein JA, Ishizaki T, Chiba K, de Morais SM, Bell D, et al. (1997) Frequencies of the defective CYP2C19 alleles responsible for the mephenytoin poor metabolizer phenotype in various Oriental, Caucasian, Saudi Arabian and American black populations. Pharmacogenetics 7: 59-64

12. Horai Y, Nakano M, Ishizaki T, Ishikawa K, Zhou HH, et al. (1989) Metoprolo and mephenytoin oxidation polymorphisms in Far Eastern Oriental subjects: Japanese versus mainland Chinese. Clin Pharmacol Ther 46: 198-207.

13. Xiao ZS, Goldstein JA, Xie HG, Blaisdell J, Wang W, et al. (1997) Differences in the incidence of the CYP2C19 polymorphism affecting the S-mephenytoin phenotype in Chinese Han and Bai populations and identification of a new rare CYP2C19 mutant allele. J Pharmacol Exp Ther 281: 604-609.

14. Lamba JK, Dhiman RK, Kohli KK (1998) Genetic polymorphism of the hepatic cytochrome P450 2C19 in north Indian subjects. Clin Pharmacol Ther 63: 422 427 .

15. Rosemary J, Adithan C, Padmaja N, Shashindran CH, Gerard N, et al. (2005) The effect of the CYP2C19 genotype on the hydroxylation index of omeprazole in South Indians. Eur J Clin Pharmacol 61: 19-23.

16. Roh HK, Dahl ML, Tybring G, Yamada H, Cha YN, et al. (1996) CYP2C19 genotype and phenotype determined by omeprazole in a Korean population. Pharmacogenetics 6: 547-551.

17. Hsu HL, Woad KJ, Woodfield DG, Helsby NA (2008) A high incidence of polymorphic CYP2C19 variants in archival blood samples from Papua New Guinea. Hum Genomics 3: 17-23.

18. Kaneko A, Kaneko O, Taleo G, Björkman A, Kobayakawa T (1997) High frequencies of CYP2C19 mutations and poor metabolism of proguanil in Vanuatu. Lancet 349: 921-922.

19. Population Distribution and Basic Demographic Characteristic Report 2010 (2011) In Departement of Statistic Malaysia.

20. A study of Adverse Drug Reactions in Malaysian Children Reported to National Pharmaceutical Control Bureau (NPCB), Ministry of Health Malaysia (2006) In NPC Bureau ed Malaysian Adverse Drug Reactions Newsletter.

21. Excoffier L, Slatkin M (1995) Maximum-likelihood estimation of molecular haplotype frequencies in a diploid population. Molecular Biology Evolution 12: 921-927.

22. Barrett JC, Fry B, Maller J, Daly MJ (2005) Haploview: analysis and visualization of LD and haplotype maps. Bioinformatics 21: 263-265.

23. NCVD-ACS Registry 1st Annual Report 2006. In National Cardiovascular Disease Database (2006) NCVD-ACS Registry, Malaysia.

24. Sherry ST, Ward MH, Kholodov M, Baker J, Phan L, et al. (2001) dbSNP: the NCBI database of genetic variation. Nucleic Acids Res 29: 308-311.

25. Zhou Q, Yu XM, Lin HB, Wang L, Yun QZ, et al. (2009) Genetic polymorphism, linkage disequilibrium, haplotype structure and novel allele analysis of CYP2C19 and CYP2D6 in Han Chinese. The pharmacogenomics journal 9 : 380-394.

26. Al-Jenoobi FI, Alkharfy KM, Alghamdi AM, Bagulb KM, Al-Mohizea AM, et al. (2013) CYP2C19 genetic polymorphism in Saudi Arabians. Basic Clin Pharmacol Toxicol 112: 50-54. 